\title{
ARSENICAL ENCEPHALOPATHY OCCURRING IN THE TREATMENT OF LUES DURING PREGNANCY
}

\author{
BY \\ ROBERT LEES and J. R. G. BUCHANAN \\ Manchester and Leeds
}

The dangers of treatment of syphilis are often minimized ; one of the most serious complications of arsenical treatment is encephalopathy. This complication is rare, but is associated with a high mortality. There is apparently some difference of opinion and experience regarding the increased hazards of treatment of lues during pregnancy. Earle Moore and others (1948) emphasize the rarity of arsenical encephalopathy during pregnancy provided there is close supervision. Batchelor (1949) states that pregnancy increases the risk of toxic effects. Stokes emphasizes the possibility of arsenical encephalopathy being confused with toxaemia of pregnancy, insisting that stringent observation and precautions against the toxic effects of arsenicals must be observed.

The purpose of this communication is to report two fatal cases of arsenical encephalopathy in pregnant women, and to advocate a scheme of treatment which excludes arsenical drugs during pregnancy. The two cases occurred in a series of 256 pregnant women treated for syphilis in Leeds United Hospitals during the two years 1947-1949.

\section{Case Reports}

Case 1.-An unmarried woman aged 23 years was brought to the ante-natal department at the end of the eighth month of pregnancy. Her blood gave a strongly positive Wassermann reaction. Her cervix was extensively ulcerated and the superficial lymph glands were enlarged. There were no skin or mouth lesions. Exudate from an ulcer on the cervix was tested for $T$. pallidum, but none could be detected. A diagnosis of early syphilis (late primary) was made, and she was admitted to hospital for isolation. As her confinement was expected within three weeks, and her general physique and condition was good, it was decided to give her very intensive treatment. She was given penicillin in oil-wax suspension 0.5 mega units night and morning, and also mapharside $\mathbf{0 . 0 6} \mathrm{g}$. daily for five days. Her condition remained good, she had no symptoms, and her temperature was normal throughout treatment, so that she was discharged from hospital on 24.9.47 and instructed to return for further observation.

On 26.9.47 she was re-admitted in a semi-comatose state, stupor having started that day. She had a series of twelve epileptiform convulsions. On examination the pupils were contracted, equal in size and reacted to light. The arm, knee, and ankle jerks were exaggerated, and the plantar reflexes were extensor. There was no oedema, the urine was free from albumin, and the blood pressure was $100 / 70$. Her temperature rose steadily and reached $105.6^{\circ} \mathrm{F}$. The foetal heart-beat became rapid and weak, and ceased about 12 hours after admission. The coma deepened and in spite of treatment with B.A.L. (dimercaptol) and stimulants, she died approximately 2 days after the onset of symptoms, and 4 days after the last injection of mapharside. The cerebrospinal fluid was examined soon after admission on 26.9.47. The pressure was not increased, there was no blood present, and the Wassermann reaction was negative. Unfortunately the specimen was not sent for chemical tests.

Post-mortem examination showed the characteristic changes of arsenical encephalopathy.

Case 2. (49/117).-A married woman aged 36, with three children, gave a positive blood Wassermann reaction during routine ante-natal tests. Confirmatory tests by several other methods were also positive. The Ministry of Health Reference Laboratory reported Wassermann reaction positive, Kahn test positive, Price precipitation reaction positive with serum diluted 1:2. Her husband also had a positive Wassermann reaction. The origin and duration of the disease are unknown. The husband was a late syphilitic, but all three children gave negative blood tests. Clinical examination of the mother revealed no clear evidence of lues. She was in the 6th month of pregnancy and it was decided to admit her to hospital where she received penicillin 10 mega units between 16.3.49 and 26.3.49. She subsequently attended as an out-patient and was given neoarsphenamine $0.3 \mathrm{~g}$. and bismuth $0.2 \mathrm{~g}$. on 2.4 .49 , and neoarsphenamine $0.45 \mathrm{~g}$. and bismuth $0.2 \mathrm{~g}$. on 9.4.49.

Two days later (11.4.49), she had a severe headache on waking, this increased in severity until mid-day when she went to bed. She became stuporous and found that 
she could not stand. She vomited repeatedly during the night. Next day (13.4.49) she was still talking coherently but tended to lapse into a light stupor; she was drowsy and her speech became mumbling and indistinct: Medical aid was now called and she was admitted to hospital at noon. On examination she was seen to be in light coma, her colour was grey and the lips cyanosed. The left side was flaccid and apparently paralysed. There were no muscular twitchings or convulsions. She had not albuminuria or oedema, and her blood pressure was not raised. The temperature was normal. Lumbar puncture was done ; the cerebrospinal fluid was not under pressure nor blood-stained. The laboratory reported on the specimen as follows: cell count, 2 per c.mm.; Wassermann reaction, positive ; protein, $180 \mathrm{mg} . / 100 \mathrm{ml}$.; Lange gold sol, 5554321000.

She was treated by injections of BAL (dimercaptol) and stimulants. Her coma deepened, but she went into labour and a live child, weighing $4 \mathrm{lb}$., was born. This child still survives, and has remained sero-negative to date (15.6.50). The patient gradually became deeply unconscious and died on 14.4.49, approximately 48 hours after the onset of symptoms and four days after the last injection of an arsenical drug. Post-mortem examination revealed the typical signs of arsenical encephalopathy.

\section{Discussion}

No other cases of arsenical encephalopathy have occurred in the large syphilis clinic in Leeds during the period named. In the first case the encephalopathy was ascribed to the intensity of treatment with arsenoxide, this being a common finding during the war. This reason cannot be given for the second case, but it is possible that the simultaneous use of neoarsphenamine and bismuth may increase the risk of toxic effects of drugs during pregnancy. We are often tempted to give the mother as much treatment as possible during pregnancy as she is likely to cease attending after confinement.

It is now clear (Earle Moore and others, 1948), that treatment of syphilis during pregnancy by adequate amounts of penicillin will secure about 99 per cent. of non-syphilitic children. Accordingly, there is little justification for exposing the expectant mother to the risks of treatment by arsenical drugs, and these should be reserved for treatment after delivery, if further treatment is required.

It is advocated, therefore, that a pregnant woman requiring treatment for syphilis should be given 10 mega units penicillin in a period of 10 days, preferably between the fourth and sixth month of pregnancy. Thereafter, she may be given treatment with bismuth, provided there is no contraindication, but high dosage should not be attempted, and an oil-soluble preparation such as stabismol is probably safer then injectio bismuthi (B.P.) or other preparations containing insoluble salts or bismuth. The penicillin may be given either as injections of 80,000 units in saline 3 -hourly, or 500,000 units in saline night and morning, or penicillin-procaine suspensions may be used once or twice daily. The technique of administration of penicillin does not appear to have affected our results in any way, and allergic manifestations are infrequent.

As our knowledge of the effects of ante-natal penicillin in preventing post-natal (congenital) syphilis in the infant is still very limited, we carry out a very thorough examination of the infant when three months old. This comprises clinical examination, serological tests, and radiological examination of the long bones. It is intended to maintain observation of the children for at least 5 years.

\section{Summary}

(1) Two cases of arsenical encephalopathy in pregnant syphilitic women are described.

(2) It is advocated that such women should be treated by peniciilin and bismuth, and that mapharside and neoarsphenamine should not be administered during pregnancy.

\section{REFERENCES}

Batchelor, R. C. L. (1949). Practitioner, 162, 369.

Moore, J. E., McElligott, G. L. M., and Lourie, E. M. (1948). British Journal of Venereal Diseases, $24,1,9,11$, and 16 . 